\title{
A função social da minissérie Grande Sertão: Veredas na construção de um sentido identitário de nação*
}

\author{
Maria Cristina Palma Mungioli \\ Doutora em Ciências da Comunicação pela Escola de Comunicações e Artes - USP, mestra em \\ Educação pela Faculdade de Educação da Universidade de São Paulo, professora doutora da \\ Escola de Comunicações e Artes - USP**. \\ E-mail: crismungioli@usp.br
}

[...] havia três sertões. O de Guimarães Rosa é uma criação verbal, literária. O sertão de Walter Avancini é uma criação e imagens em movimento, televisiva. O sertão mineiro, de verdade, dificilmente terá a magia da literatura

ou da televisão. A imaginação criadora é uma feiticeira

inesgotável e deixa-nos fascinados pela beleza, vibração e sensibilidade da obra de arte que é o seriado***.

Resumo: Discutimos um dos temas tratados em nossa tese de doutorado**** que teve como objetivo principal compreender um sentido identitário de nação construído pela minissérie Grande Sertão: Veredas, por meio de gêneros e temas. O referencial teórico e os procedimentos adotados possibilitaram compreender a articulação entre gêneros literários, gêneros do discurso, gêneros televisuais e acabamento temático, numa perspectiva de construção histórica de um sentido de nação socialmente determinado. Neste artigo, detemo-nos em um dos aspectos estudados em nossa pesquisa, o qual analisamos como uma espécie de caráter missionário da minissérie, atribuído-lhe por meio de discursos de diretores, produtores e pela imprensa especializada em televisão. Neste quadro,
Abstract: We discuss in this article one of the themes studied during our Doctorate thesis which main purpose was to realize a sense of identity regarding the nation, built by the Miniseries Grande Sertão: Veredas by means of genres and themes. The theoretical reference and the adopted procedures made possible to understand the articulation among literary genres, speech genres, televisual genres and thematic orientation within a perspective of historic construction of a sense of nation socially determined. In this article, we focus on one of the studied aspects in our research, in which we analyze it as a sort of missionary element in the series, given by discourses of directors, producers and by the specialized press in television. In this scenario, we've tried to
Recebido: 21.10 .2008

Aprovado: 08.05.2009

* Versão reduzida e modificada do trabalho Minissérie Grande Sertão: Veredas: gêneros e temas construindo um sentido identitário de nação, selecionado para o VII Encontro dos Núcleos de Pesquisa em Comunicação - NP, Ficção Seriada, do XXX Congresso Intercom, realizado em Santos, SP, em 2007

** Disponível em: <http:// lattes.cnpq.br/726475878 8782605>

*** ANDRADE, Carlos Drummond de. Magia do sertão televisivo. Globo, 23 nov. 1985

$\star \star \star \star$ A tese Minissérie Grande Sertão: Veredas: gêneros e temas construindo um sentido identitário de nação foi apresentada pela autora, em setembro de 2006 como parte dos requisitos para obtenção do título de doutora em Ciências da Comunicação na ECA-USP. 
procuramos entender a função social da minissérie na construção de um sentido de nacionalidade por meio de discursos e imagens televisuais que pretendiam mostrar o Brasil aos brasileiros.

Palavras-chave: minissérie Grande Sertão: Veredas, gêneros televisuais, teledramaturgia, sentido identitário, nação e televisão. figure out the social function of the series in the construction of a sense of nationality by using discourses and televisual images that intended to show Brazil to Brazilians.

Keywords: Miniserie Grande Sertão: Veredas, televisual genres, teledramaturgy, sense of identity, nation and television.

Apesar de ter sido exibida há quase 25 anos pela Rede Globo, a minissérie Grande Sertão: Veredas continua sendo objeto de pesquisa e de discussão nos meios acadêmicos, seja por meio de dissertações e teses, seja pela apresentação de trabalhos em seminários e congressos de comunicação, seja, ainda, em congressos e colóquios que, mais especificamente, tratam da obra de Guimarães Rosa. Nos meios de comunicação em geral, a minissérie é citada, com frequên-

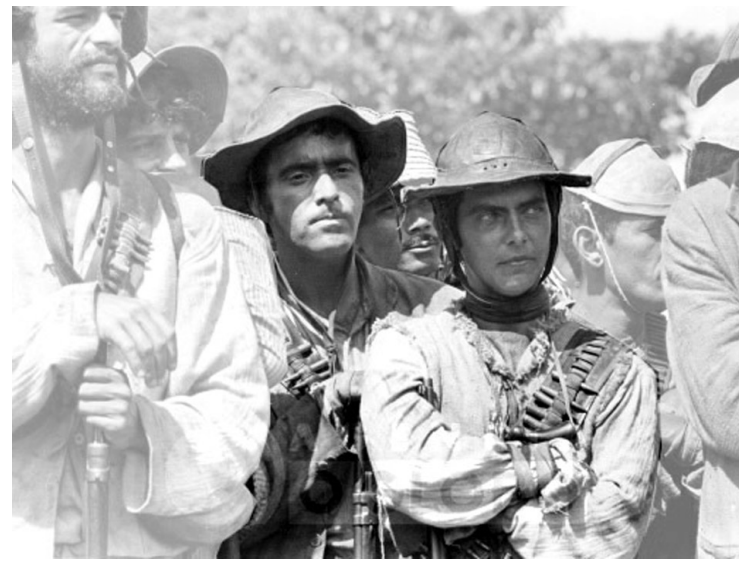

Grande Sertão: Veredas, no destaque os atores Tony Ramos e Bruna Lombardi. Disponível em: $<$ http://oliquidificador.wordpress.com/2009/04/>

cia, como um marco da teledramaturgia brasileira e, muitas vezes, serve como exemplo de um padrão de qualidade da programação televisiva. A importância que essa adaptação pioneira de Grande Sertão: Veredas adquiriu para a Rede Globo de Televisão e para a produção televisual brasileira pode ser demonstrada pelo destaque que lhe é dado pela emissora em eventos que tratam de televisão em diversas partes do mundo. Apenas para citarmos um exemplo, em 2001 a minissérie fez parte da mostra Brazil on Screen, realizada pelo Museu Guggenhein de Nova York, juntamente com os filmes Auto da Compadecida e Orfeu e a minissérie $A$ invenção do Brasil - produções relativamente recentes que obtiveram, em geral, boa aceitação de público e de crítica.

A história de Riobaldo contada em 25 capítulos, de 18 de novembro a 20 de dezembro de 1985, é fruto da adaptação de Walter George Durst, responsável também pelo roteiro, com colaboração de José Antonio de Souza, do romance Grande Sertão: Veredas, de Guimarães Rosa. Roteiro final e direção foram assinados por Walter Avancini. A minissérie foi apontada por seus realizadores (incluindo adaptador, roteiristas, diretores e produtores) como um ato de coragem, pois buscou transportar o sertão de Guimarães Rosa para o meio televisual. Os problemas para a transposição não seriam apenas de ordem técnica, mas decorreriam, sobretudo, da dificuldade de se adaptar uma obra considerada de difícil leitura para o principal meio de comunicação de massa de nosso País. 
A escolha de transpor obras de reconhecido valor estético-literário para o meio televisivo apresenta possivelmente uma série de motivações que vão desde a construção de uma imagem de marca da Rede Globo de Televisão até a sua consolidação como produtora da indústria cultural numa perspectiva mundial. A criação e a consolidação de uma imagem de marca ocorrem em diversas frentes e podem repercutir no plano nacional ou internacional.

No Brasil, entretanto, a consolidação da televisão como meio de comunicação de massa tem lugar por meio de um processo em que a televisão privada assume para si um "papel social, nacional e cultural" e passa a ser "a vitrina" do País, conforme afirma Wolton ${ }^{1}$.

Em razão das injunções antes delineadas, adotamos na pesquisa uma abordagem transdisciplinar com o objetivo de não apenas correlacionar os diversos sujeitos e objetos da comunicação, mas também de concebê-los e analisá-los dentro da complexa teia das relações sociais. A técnica de pesquisa adotada foi o estudo de caso.

O trabalho de análise envolveu duas perspectivas: a do discurso como constituinte do gênero e a do próprio gênero (minissérie) dentro da intertextualidade que se estabelece entre os produtos simbólicos de uma cultura; no caso, os da cultura televisual. Para isso, estudamos não só a minissérie, mas também todo o material que dela tratasse nos jornais e revistas de grande circulação nas cidades do Rio de Janeiro e São Paulo.

Neste artigo, detemos nosso olhar em um dos aspectos estudados em nossa pesquisa, o qual analisamos como uma espécie de caráter missionário da minissérie, atribuído-lhe por meio de discursos de diretores, produtores e pela imprensa especializada em televisão. Dentro desse quadro, procuramos entender a função social da minissérie na construção de um sentido de nacionalidade por meio de discursos e imagens televisuais que pretendiam mostrar o Brasil aos brasileiros.

\section{MINISSÉRIE GRANDE SERTÃO: VEREDAS - CONTEXTO E PRETEXTO}

O ano de 1985, na Rede Globo de Televisão, é marcado por produções que tratam de questões referentes à formação do Brasil como nação e à transformação de sua população em povo². As minisséries produzidas nesse ano são adaptações de grandes obras da literatura brasileira que versam sobre a constituição do povo e da nação. O tempo e o vento $(22.04 \text { a } 31.05 .1985)^{3}$, Tenda dos milagres (29.07 a 06.09.1985) ${ }^{4}$ e Grande Sertão: Veredas (18.11 a 20.12.1985) mostram as lutas pela terra e pela cidadania permeadas pelos interesses políticos e econômicos. Enfim, os problemas e anseios dos brasileiros ganham vida por meio da emoção, da ficção, da teledramaturgia. A produção e a exibição de forma contínua de três minisséries com fortes características históricas formaram uma espécie de painel da história e da cultura brasileira. No aspecto
1. A consolidação das redes de emissoras de televisão como representantes de um sentimento de nacionalismo na América Latina e no Brasil é amplamente discutida por vários autores. Ver: MARTÍN-BARBERO，J.; REY, German. Os exercícios do ver. São Paulo: Editora Senac, 2001; ORTIZ, R.; BORELLI, S. H. S.; RAMOS, J. M. O. Telenovela: história e produção. São Paulo: Brasiliense, 1988; WOLTON, Dominique. Elogio do grande público. São Paulo: Ática. 1996. p. 154, entre outros.

2. Seguindo definição de Octávio lanni, considera-se população como uma pluralidade de raças e mesclas; povo, como uma coletividade de cidadãos (cf. A ideia do Brasil moderno. São Paulo: Brasiliense, 2004).

3. Escrita por Doc Comparato, com colaboração de Regina Braga, baseada na obra de Érico Veríssimo. Direção de Paulo José.

4. Escrita por Aguinaldo Silva e Regina Braga, baseada na obra homônima de Jorge Amado. Direção de Paulo Afonso Grisoli.

5. De Walter George Durst, com a colaboração de José Antonio de Souza. Direção de Walter Avancini e supervisão de Daniel Filho. 
comunicação \& educação • Ano XIV • Número 3 • set/dez 2009

temático, as minisséries produzidas até então pela Rede Globo compunham um painel de tramas urbanas e regionais cujo ponto comum era tentar fotografar a heterogeneidade da alma brasileira.

Ocorre também em 1985 a convocação de eleições para a Assembleia Nacional Constituinte, que se realizariam em 1986. Cenário propício, portanto, a questionamentos em torno de temas e problemas nacionais. A minissérie surge no momento em que o País se discutia como nação e buscava se reorganizar sobre os pilares da democracia representativa. Assim, a busca pela compreensão da identidade brasileira não era uma preocupação descolada da realidade, e sim uma busca que reverberava, em certa medida, os anseios da nação brasileira.

No mesmo ano, a telenovela Roque Santeiro, de Dias Gomes, colocava na ordem do dia assuntos como corrupção, coronelismo, mistificação da realidade, conforme atestam diversas reportagens da época. Essa preocupação em mostrar o Brasil ao Brasil de maneira autêntica fica clara em entrevista de Dias Gomes ao jornal Folha de S. Paulo, em 16.08.1985, em que o autor justifica o sucesso da temática rural em algumas minisséries afirmando que: "A grande cidade é cosmopolita, ela não reflete bem a autenticidade que se vê no campo; por isso o rural é a fonte mais autêntica de representação de brasilidade" ${ }^{6}$. Pode-se dizer que esse discurso se assemelha muito ao de Avancini, no prólogo da minissérie Grande Sertão: Veredas, quando o diretor afirma que "um pouco da obra de Guimarães Rosa nos aproxima a todos do coletivo brasileiro”. É o Brasil que busca suas raízes culturais e se discute como nação por meio da televisão.

Para bem compreendermos o clima político e a imagem da Rede Globo que predominavam em 1985, é preciso que retornemos a 1984, ano de eclosão da campanha das $D i$ retas já que mobilizou, nas principais capitais brasileiras, multidões de manifestantes a favor da aprovação da emenda constitucional para a realização de eleições

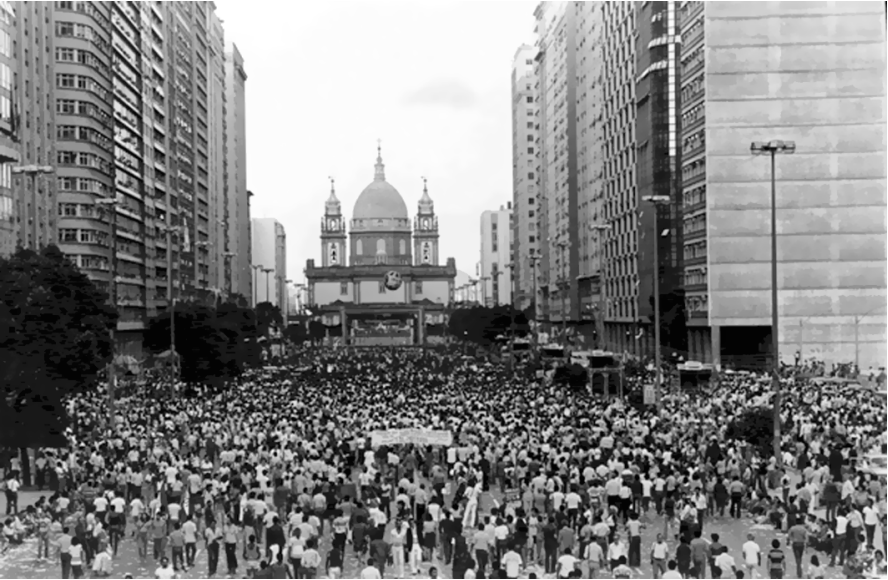

Comício das Diretas Já, na Av. Presidente Vargas, tendo ao fundo a Igreja da Candelária, 10 de agosto de 1984 Disponível em: <http://www.alerj.rj.gov.br/livro/pag_168.htm>
6. Cf. LOBO N. J. F. Ficção e política: o Brasil nas minisséries. Manaus: Editora Valer, 2000. p. 96. diretas para presidente da República. Comícios de caráter suprapartidário reuniram milhões de pessoas em todo o Brasil, principalmente em São Paulo e no Rio de Janeiro.

Entretanto, a Rede Globo, afinada com o governo militar, apresentava superficialmente algumas dessas manifestações apenas em seus jornais locais, o que gerou insatisfação dos partidários do movimento e da opinião pública. A situação piorou ainda mais quando a emissora noticiou um comício gigantesco 
ocorrido na Praça da Sé, em São Paulo, como comemoração pelo aniversário da cidade, omitindo que se tratava de uma manifestação pelas eleições diretas. Tratava-se, portanto, não apenas de uma omissão, mas, principalmente, de uma informação distorcida. Foi somente a partir das repercussões negativas ocasionadas por esses fatos que a emissora passou a dedicar espaço em seu noticiário nacional para tratar do movimento que continuou a crescer de maneira vertiginosa em todo o País.

É preciso que se observe, no entanto, que a resposta da Rede Globo mais incisiva a tais críticas ocorreu em 11 de abril de 1984, quando a emissora interrompeu a apresentação de um capítulo da telenovela Champagne para apresentar ao vivo o final de um comício pelas Diretas Já que se realizava na Candelária no Rio de Janeiro ${ }^{7}$. Entretanto, essa mudança na cobertura jornalística não impediu que equipes de reportagem da Rede Globo fossem hostilizadas nos comícios subsequentes ${ }^{8}$. Apesar desse redirecionamento, pode-se dizer que sua imagem como defensora da nacionalidade brasileira e dos valores nacionais, que vinha sendo consolidada desde sua fundação, sofreu um forte revés.

Assim, era de supor que 1985, ano em que a emissora comemoraria seu vigésimo aniversário, fosse marcado pelas cores nacionais, principalmente na teledramaturgia, segmento de maior audiência da emissora e, historicamente, responsável pela conquista da hegemonia no mercado televisual brasileiro. Portanto, o contexto sociopolítico que marcou toda a primeira metade da década de 1980 - abertura política, crise econômica, fortalecimento de partidos políticos, eleições diretas para governadores, movimentos organizados pela volta ao estado de direito, que envolvia os partidos políticos de oposição, discussão sobre alinhamento da Rede Globo com os regimes militares e a sua consolidação como líder absoluta de audiência - forneceu pretexto para a realização das minisséries com fortes cores nacionais que comemoraram os vinte anos da emissora.

\section{A FUNÇÃO SOCIAL DA MINISSÉRIE GRANDE SERTÃO: VEREDAS}

O estudo do corpus dos discursos do material jornalístico revelou certa tendência da imprensa em entender que a minissérie, além de valor estético, possuía um valor social, pois levava ao grande público uma obra-prima da literatura. Consideramos essa dimensão atribuída à minissérie pela imprensa e pelos seus próprios artífices como decorrência de uma função social, o que possibilita dimensionar o valor simbólico ${ }^{9}$ da minissérie dentro do contexto da produção televisual brasileira, principalmente em relação à década de 1980, e do gênero minissérie em geral.

Para Antonio Candido, "a função social comporta o papel que a obra desempenha no estabelecimento de relações sociais, na satisfação de necessidades espirituais e materiais, na manutenção ou mudança de certa ordem na sociedade" ${ }^{10}$. Entretanto, segundo o autor, a correlação entre o pretendido e o alcançado, perpassada pela dimensão ideológica, não se realiza pela criação
7. NO RIO, mais de $1 \mathrm{mi}-$ Ihão pelas diretas. Folha de S. Paulo, 11 abr. 1984 Disponível em: <http:// almanaque.folha.uol.com br/brasil_11abr1984.htm>. Acesso em: 10 maio 2006.

8. SÃo PAULO faz o maior comício. Folha de S. Paulo, 17 abr. 1984 Disponivel em: <http:// almanaque.folha.uol.com. br/brasil17abr1984.htm>. Acesso em: 10 maio 2006.

9. BOURDIEU, P. As regras da arte: gênese e estrutura do campo literário. São Paulo: Cia. das Letras, 2005

10. CANDIDO, Antonio. Literatura e sociedade. São Paulo: Cia. Editora Nacional, 1965. p. 55. 
11. LARA RESENDE, Luís (Dir.-ed.). Press Release: boletim de programação da Rede Globo. Rio de Janeiro: Rede Globo, $p$. 8, nov. 1985.

12. DURST, W. G. Especialização da TV/Espacialização do sentido. In: PACHECO, Elza Dias (Org.). Televisão, criança, imaginário e educação. Campinas/SP: Papirus, 1998. p. $122-123$

13. O termo paratexto, desenvolvido por Gerard Genette, em Seuil (1979), refere-se ao conjunto dos discursos contendo comentários, apresentações ou acompanhamento sobre uma obra, seja ele feito por seu autor, seja por críticos especializados ou mesmo na imprensa em geral. e atuação do autor ou do público envolvido, mas é resultado de uma série de injunções presentes na sociedade.

Assim, os discursos que antecederam, perpassaram e comentaram a posteriori a minissérie são extremamente importantes para compreendermos sua função social e ideológica no complexo quadro da sociedade brasileira e, mais especificamente, da indústria cultural brasileira.

A visão missionária do papel da minissérie pode ser notada no depoimento de Avancini:

O trabalho foi enorme [...]. E depois disso eu afirmo que, se conseguir $15 \%$ da obra de Guimarães Rosa, acho que já é um percentual excelente, dentro desse processo industrial. Com mais tempo talvez eu chegasse a uns 30\%. Com o tempo ideal, quiçá $40 \%$ do que essa obra pede, o que seria uma margem maravilhosa para quem conhece o gabarito de Guimarães Rosa. Mas são muito poucos os que conhecem e não foi para estes que fiz o programa. Assim não importa que se frustrem. Eu também me frustro. O que me importa é que a grande maioria do público, que jamais teve qualquer contato com Guimarães Rosa, sinta um pouco do prazer de conhecê-lo ${ }^{11}$.

É praticamente a mesma compreensão da função social da minissérie que se depreende da afirmação de Durst (1998: 122-123), em artigo de 1998, abordando a relação entre televisão e educação e, de certa forma, o papel social da televisão:

A TV chega à gente simples, é compreendida por iletrados e vista por analfabetos. Adaptei romances de nossa literatura, como Grande sertão: Veredas e Gabriela. Quando o conteúdo desses livros chegaria ao povão se não fosse a TV? Temo que nunca, neste nosso país fantástico de ditaduras que persistem até hoje. Não é uma forma de suprimir a liberdade, impedir de pensar? ${ }^{12}$

Walter Avancini apresenta pessoalmente, no formato de prólogo, a minissérie Grande Sertão: Veredas atribuindo-lhe por meio de seu discurso uma espécie de missão educativa, na medida em que ela proporcionaria à imensa maioria dos brasileiros o acesso à grande literatura, para que assim o Brasil pudesse se (re)conhecer como nação. Avancini enaltece a grandeza da obra de Guimarães Rosa ao mesmo que tempo que elogia a coragem dos criadores e dos produtores da minissérie. Além disso, o prólogo, gravado na Biblioteca Nacional, constrói uma identificação da minissérie com o prestígio dessa instituição e proporciona uma relação direta entre minissérie e obra literária.

No prólogo, Avancini também demonstra sua preocupação com a fidelidade ao texto-fonte, o romance Grande Sertão: Veredas: "Trabalhamos muito, muito mesmo, em busca da fidelidade que a obra merece". O caráter paratextual ${ }^{13}$ do prólogo se evidencia por meio do discurso que procura qualificar o produto apresentado como um legítimo intérprete do romance de Guimarães Rosa e, portanto, merecedor da mesma recepção que a obra literária obteve por parte da crítica e do público. Em nossa pesquisa, verificamos que a maior parte dos críticos de televisão e de literatura reconheceu a fidelidade ao texto-fonte como uma das qualidades da minissérie. 
A função social da minissérie decorre de fatores muito distintos que envolvem aspectos referentes tanto à manutenção da hegemonia da emissora quanto a uma espécie de sentimento (explicitado pelo diretor, adaptador e artistas envolvidos) missionário de civilizar a população brasileira; porém, passa também pela chancela de qualidade que lhe foi outorgada pela imprensa, conforme verificamos em nossa pesquisa. População essa privada de uma política cultural (e também educacional) de maior qualidade que lhe propiciasse o acesso não só aos grandes escritores, mas também ao mundo das letras e, por conseguinte, aos principais temas sociais que afligem o País. Trata-se, pois, de encarar a produção televisual como forma de a população adquirir a nacionalidade brasileira, supostamente presente na literatura, principalmente na grande literatura brasileira. Nacionalidade (e literatura) somente acessível por meio dos programas de televisão, já que as outras instituições não conseguem - ou não querem - fazer com que a população ascenda à cultura de qualidade representada pela literatura dos grandes escritores brasileiros.

As preocupações pedagógicas e até mesmo civilizatórias dos autores da minissérie, encontradas em diversas entrevistas contemporâneas e em depoimentos posteriores a ela, revelam em grande medida o papel social que lhe foi atribuído. Entretanto, cabe-nos ainda indagar com quais conceitos de nação e educação dialoga a função pedagógica atribuída à minissérie (e até mesmo à literatura) e, por conseguinte, à televisão dentro dessa perspectiva civilizatória. Dito de outra forma, como, por meio do estudo dos discursos de seus autores, torna-se possível delinear uma compreensão da função social de um produto da indústria cultural e de um meio de comunicação como espaço de construção de uma nacionalidade fundada sobre as narrativas televisuais?

\section{EM BUSCA DA NAÇÃO E DA EDUCAÇÃO}

Os conceitos de nação e de povo não se constroem no vazio. É necessário que haja um laço social que permita às populações de um determinado país sentir-se como povo e como nação. Boa parte desse laço social é obtido por meio " $[\mathrm{d}]$ as narrativas com as quais se reconhecem, tecem, enaltecem ou esquecem os mais diferentes aspectos da formação e da transformação da sociedade nacional [...]"14. O Brasil (como todos os países) passou (e passa) por diversos momentos em que se procurou (procura) criar/consolidar a ideia de nação a partir de narrativas literárias que buscavam (e buscam) criar no imaginário da população o conceito de nação ${ }^{15}$. Em todos esses momentos e, talvez, para todos esses momentos houve uma narrativa que correspondesse à busca de um sentimento de nacionalidade que expressasse o caráter único das várias populações que viviam dentro de nossas fronteiras.

No Brasil, os meios de comunicação de massa ocupam papel de destaque na constituição dessa consciência de nacionalidade ${ }^{16}$. O anseio de forjar, com a ajuda desses meios, a identidade brasileira como nação e como povo é fortemente evidenciado também pelos discursos e pelas ações dos governos militares
14. IANNI, O. Nação e narração. In: AGUIAR Flávio (Org.). Antonio Candido: pensamento e militância. São Paulo: Editora Perseu Abramo/ Humanitas/FFLCH/USP, 1999. p. 71.

15. Cf. CANDIDO, Antonio. Literatura e sociedade. São Paulo: Cia. Editora Nacional, 1965 Formação da literatura no Brasil: momentos decisivos. Belo Horizonte: Ed. Itatiaia; São Paulo: EDUSP, 1975. v. I e II COUTINHO, Afrânio. A tradição afortunada: espírito da nacionalidade na crítica brasileira. Rio de Janeiro: Livraria José Olímpio; São Paulo: EDUSP, 1968; BOSI, Alfredo. A dialética da colonização. São Paulo: Cia. das Letras, 1992.

16. MARTÍN-BARBERO REY, Os exercícios do ver..., cit. 
comunicação \& educação • Ano XIV • Número 3 • set/dez 2009

17. ORTIZ; BORELLI; RAMOS, Telenovela..., cit.

18. IANNI, O. A ideia de Brasil moderno. São Paulo: Brasiliense, 2004. p. 180

19. Sobre as discussões respeito do sentimento de nacionalismo e de integração nacional (sobretudo na América do Sul), ver: MARTÍN-BARBERO. Dos meios às mediações: comunicação cultura e hegemonia. Rio de Janeiro: Editora UFRJ, 2001, principalmente a terceira parte do livro. pós-1964 ${ }^{17}$. Entretanto, mesmo nos dias atuais, a definição do Brasil como nação ainda parece algo incerto para Ianni, que afirma: "É como se estivesse espalhada no espaço, dispersa no tempo, buscando conformar-se ao nome, encontrar-se com a própria imagem, transformar-se em conceito"18.

Mas como a nação pode se encontrar com a própria imagem, como se transformar em conceito, como definir sua fisionomia? Avancini, no prólogo da minissérie, oferece uma pista: "[...] porque um pouco de Guimarães Rosa nos aproximará a todos do coletivo brasileiro". A identidade brasileira ganha corpo e se firma não apenas por meio da literatura - cuja penetração, num país com população pouco "afeita à leitura" e no qual há grande número de analfabetos, é pequena -, mas também, e talvez principalmente, pelas imagens vistas por milhões de brasileiros nas telas de televisão. Ficam claras as intenções pedagógicas do diretor quanto afirma, no prólogo à minissérie, que a transposição do livro para a televisão tem dois significados: " $1^{\circ}$ ) estimular para os que sabem ler uma aproximação com o belo mundo de Guimarães Rosa; e $2^{\circ}$ ) levar para a grande maioria do público brasileiro ainda, infelizmente, sem acesso ao mundo das letras pelo menos um esboço desse magnífico universo".

Diversos estudiosos têm chamado a atenção para o fato de a televisão no Brasil e na América Latina ${ }^{19}$ possuir um caráter bastante diverso daquele encontrado na Europa ou nos Estados Unidos da América. Apesar de ter nascido sob a égide da iniciativa privada, sempre esteve intimamente ligada às estruturas governamentais quer no sentido político do termo, quer no sentido de apropriação de um ideário pedagógico dos meios de comunicação de massa elevados a uma categoria um tanto quanto discutível de educadores do Brasil. No primeiro sentido, estamos nos referindo, principalmente, ao formidável aparato tecnológico fornecido pelo Estado para que as imagens de televisão ganhem os lares de todos os brasileiros. O melhor exemplo disso é a criação, pelos sucessivos governos da Ditadura Militar, de uma ampla rede de telecomunicações com a finalidade de integrar o País por meio de redes nacionais de televisão.

No segundo sentido, que também é político, referimo-nos à forte influência de governos, principalmente os autoritários, na criação e veiculação de programas de televisão visando à valorização daquilo que se considera a verdadeira cultura brasileira (aquela que se identifica com as elites e com um saber escolarizado, institucionalizado). Essa influência ocorre principalmente em razão do sistema de concessão de canais em vigor no País, por meio do qual a autorização de funcionamento de um canal de TV é concedida pelo governo.

$\mathrm{Na}$ confluência dessas visões e intimamente relacionada à questão da busca da nacionalidade por meio das cores locais das produções televisuais, encontra-se uma espécie de preocupação pedagógica dos autores da minissérie de considerar seu trabalho uma forma de proporcionar aos brasileiros incultos a possibilidade de conhecer um dos maiores romances brasileiros de todos os tempos.

Em nosso trabalho, consideramos pedagógicos os discursos encontrados no corpus que defendem a veiculação da minissérie Grande Sertão: Veredas pelo 
seu caráter intrinsecamente educativo. Subjacente a esse discurso, encontra-se a ideia, bastante difundida na sociedade brasileira, de ação formadora dos meios de comunicação de massa num país de analfabetos. Em geral, essa avaliação funcional dos objetivos dos meios de comunicação não se restringe somente a eles, mas se dirige, em geral, à produção artística como um todo.

Verificamos, contudo, que o êxito de crítica e de audiência obtido pela minissérie Grande Sertão: Veredas não ocorreu devido à adoção de um estilo didático de apresentar as lutas de poder e de amor de Riobaldo, mas sobretudo pela capacidade de seus autores de transformar a linguagem polifônica do romance rosiano em linguagem televisual, criando/recriando o universo sertanejo numa perspectiva ao mesmo tempo brutal e humana do jagunço. Homem capaz das maiores violências, mas também de observar a beleza dos pássaros ou de jogar bilboquê.

Nesse sentido, muito mais importante que o discurso monológico e moralizador em defesa dos bons valores, surge o tratamento artístico de problemas cotidianos identificados com a realidade do telespectador; e se nem sempre ocorre numa perspectiva de transformação, pelos menos coloca em pauta algumas facetas das mais perversas relações de poder presentes em nossa sociedade (corrupção, pedofilia, violência doméstica).

É, portanto, dentro desse universo multifacetado, em que a alteridade e a dialogia devem estar presentes para que se consiga não apenas entreter, mas também fazer pensar e fazer conhecer, que se insere a minissérie, uma vez que evidencia as relações de poder entre o bando de jagunços, entre os fazendeiros e os chefes de bando e jagunços, entre homem e mulher, entre os mais miseráveis.

\section{A NAÇÃO NA MINISSÉRIE - A MINISSÉRIE NA NAÇÃO: O MODERNO E O ARCAICO}

Bhabha propõe o entendimento do conceito de nacionalidade "[...] como uma forma de afiliação social e textual [...]"20 que se opõe ao conceito de nacionalismo como certeza histórica e natureza estável. Ele postula que o importante para compreendermos a nacionalidade e o nacionalismo é termos a noção de localidade da cultura. Localidade que não encontra referência apenas no mundo "real", mas principalmente num conjunto de sentimentos que emerge nas relações humanas, notadamente naquelas em que a narrativa da nação surge como força aglutinadora, como metáfora da própria nação.

De acordo com esse pensador, as grandes obras literárias seriam metáforas da nação - a interpretação dessas obras literárias seguindo um processo de comparação subjetiva característica da metáfora -, ou seja, seriam a própria nação e não apenas uma representação dela, na medida em que interpretam as diversas temporalidades das "[...] formações culturais e processos sociais sem uma lógica causal centrada" "21. Assim, o romance Grande Sertão: Veredas e a minissérie a ele dedicada são metáforas do Brasil, pois articulam as diversas
20. BHABHA, H. K. O local da cultura. Belo Horizonte: Ed. UFMG, 1998. p. 199.

21. Ibid., p. 201. 
comunicação \& educação • Ano XIV • Número 3 • set/dez 2009

22. IANNI, A ideia de Brasil..., cit., p. 63.

23. ROSA, J. G. Grande Sertão: Veredas. 19. ed. Rio de Janeiro: Nova Fronteira, 2001. p. 195.

24. José Sarney assumiu a presidência no lugar de Tancredo Neves, de quem era vice. Neves, presidente eleito indire tamente, jamais tomou posse devido a um sério problema de saúde que o levou à morte em 21 de abril de 1985. Sarney, que havia presidido o PDS, partido político aliado aos militares, torna-se, de maneira inesperada, presidente do Brasil. temporalidades da cultura brasileira e as reorganizam, atualizando-as num complexo processo de interpretação e reinterpretação dos sentimentos e desejos de parcelas da população brasileira (os jagunços, as populações dos sertões, a elite dos fazendeiros), que, metonimicamente, se projetam como parte integrante de um todo dialeticamente constituído. Ianni também chama a atenção para as diversas temporalidades e espaços envolvidos na constituição do Brasil moderno: "O país parece um mapa simultaneamente geográfico e histórico, contemporâneo e escravista, republicano, monárquico e colonial, moderno e arqueológico" ${ }^{22}$.

$\mathrm{Na}$ minissérie, evidenciam-se as diversas camadas sociais e temporais aludidas por Ianni. Temporalidades que se condensam por meio dos discursos progressistas de Zé Bebelo - marcados pelo ideal positivista -, em nome de uma nova organização político-social, contrapostos a suas ações baseadas no coronelismo e no jaguncismo; lembramos ainda os discursos e os atos de Joca Ramiro ("imperador em três alturas") ${ }^{23}$ ou as várias cenas em que ficam claros os atos de violência de Riobaldo, nos quais subjuga mulheres, em particular, e pobres, em geral (deficientes físicos e mentais, homens e crianças), para confirmar seu poder de chefe de jagunços, tal qual um cruel senhor medieval.

As diversas temporalidades mostram-se não apenas no tratamento do todo o discursivo, mas também na fala das personagens, marcada pelo passado cujo embricamento com o presente é, ao mesmo tempo, impossível e inevitável. A esses brasis mostrados na minissérie soma-se e articula-se ainda o conceito de Brasil de 1985.

Como estava o Brasil em novembro/dezembro de 1985? Parte dos sonhos de um novo Brasil já se tinha despedaçado: no plano econômico, o país mergulhara numa forte crise financeira; no plano político, o presidente José Sarney $^{24}$ tomava medidas que não satisfaziam totalmente os desejos daqueles que haviam lutado por eleições diretas e pela volta imediata ao estado de direito. Nesse entrecruzamento de temporalidades que se traduzem em formas de organização político-sociais (jaguncismo, coronelismo, federação republicana, Nova República), surge um país multiforme e até em certos momentos multidialetal (ou seria multilingual?), que se conhece por meio da literatura, da novela e da minissérie de televisão; enfim, por meio da ficção.

\section{CONSIDERAÇÕES FINAIS}

A linguagem poética e plurivocal do romance de Guimarães Rosa, transformada em minissérie, foi apresentada como um dos maiores desafios já enfrentados pelos experientes artífices da minissérie: Avancini e Durst. A eles não bastava o desejo de vencer o desafio e transformar em minissérie o talvez mais famoso e estudado romance brasileiro. Era necessário ter um objetivo, mas também não bastava o objetivo de elaborar uma obra artística de qualidade; era preciso ter um objetivo social, um objetivo formativo e educativo: levar aos brasileiros letrados e iletrados o mundo de Guimarães Rosa como forma de 
atingir o coletivo brasileiro. O princípio que regeu essa transposição foi o da fidelidade ao texto-fonte.

Buscou-se fidelidade na composição dos diálogos, na prosódia, na musicalidade sertaneja, na ambientação das cenas, na caracterização das personagens. Enfim, fidelidade acima de tudo, porque se acreditou que só assim os brasileiros teriam acesso ao Brasil, à literatura de qualidade, enfim, à nacionalidade. Nacionalidade supostamente presente na literatura brasileira e da qual estava afastada a maioria da população. Trata-se, portanto, de o Brasil se conhecer, de se reconhecer como nação e não apenas como país cujas dimensões geográficas podem ser encontradas em mapas, mas que ainda carece de transformar sua população em povo.

Foi a esse objetivo grandioso que a minissérie se propôs. Desígnio claramente ideológico presente nos discursos de Avancini e Durst: o Brasil para os brasileiros; o melhor da literatura para os iletrados; o melhor da televisão para os letrados e os iletrados. Mas como atingir o objetivo? O caminho escolhido nas veredas às vezes desérticas da programação televisiva foi o do gênero teledramatúrgico, apresentado no formato diferenciado de uma minissérie considerada inovadora em diversos aspectos e também por ter sido totalmente gravada em locação nos sertões mineiros, nos sertões de Guimarães Rosa. Em termos de linguagem televisual, as longas sequências, os grandes planos introduziram na telinha a imensidão do sertão. $\mathrm{O}$ sertão ganha a amplidão do mundo, ou, dito de outra forma, o mundo se reduz ao sertão. O ser humano se limita dentro desse universo infinito, entre as andanças de Riobaldo: não sabemos se estamos indo ou se estamos voltando; se o inimigo está longe ou à espreita. Como saber? Alguém sabe quando o bem está próximo e o mal está distante? Com quem podemos contar diante do mal? Com Deus ou com o diabo? São perguntas que nos levam para o meio do redemunho ${ }^{25}$.

\section{REFERÊNCIAS BIBLIOGRÁFICAS}

ANDRADE, Carlos Drummond de. Magia do sertão televisivo. O Globo, 23 nov. 1985.

BHABHA, H. K. O local da cultura. Belo Horizonte: Ed. UFMG, 1998.

BOURDIEU, P. As regras da arte: gênese e estrutura do campo literário. São Paulo: Cia. das Letras, 2005.

CANDIDO, Antonio. Literatura e sociedade. São Paulo: Cia. Editora Nacional, 1965.

DICIONÁRIO DA TV GLOBO. Projeto Memória das Organizações Globo. Rio de Janeiro: Jorge Zahar, 2003. v. 1: Programas de dramaturgia \& entretenimento.

DURST, W. G. Especialização da TV/Espacialização do sentido. In: PACHECO, Elza Dias (Org.). Televisão, criança, imaginário e educação. Campinas/SP: Papirus, 1998.

25. ROSA, Grande Sertão..., cit., p. 611. 
comunicação \& educação • Ano XIV • Número 3 • set/dez 2009

IANNI, O. Nação e narração. In: AGUIAR, Flávio (Org.). Antonio Candido: pensamento e militância. São Paulo: Editora Perseu Abramo: Humanitas/ FFLCH/USP, 1999.

. A ideia de Brasil moderno. São Paulo: Brasiliense, 2004.

LARA RESENDE, Luís (Dir.-ed.). Press Release: boletim de programação da Rede Globo. Rio de Janeiro: Rede Globo, nov. 1985.

LOBO, N. J. F. Ficção e política: o Brasil nas minisséries. Manaus: Editora Valer, 2000 .

MARTÍN-BARBERO, J.; REY, German. Os exercícios do ver. São Paulo: Editora Senac, 2001.

Dos meios às mediações: comunicação, cultura e hegemonia. Rio de Janeiro: Editora UFRJ, 2001.

MUNGIOLI, M. C. P. Minissérie Grande Sertão: Veredas: gêneros e temas construindo um sentido identitário de nação. Tese de doutorado. Escola de Comunicações e Artes, Universidade de São Paulo, 2006.

ORTIZ, R.; BORELLI, S. H. S.; RAMOS, J. M. O. Telenovela: história e produção. São Paulo: Brasiliense, 1988.

ROSA, J. G. Grande Sertão: Veredas. 19. ed. Rio de Janeiro: Nova Fronteira, 2001. WOLTON, Dominique. Elogio do grande público. São Paulo. Ática. 1996.

\section{Endereços eletrônicos}

$<$ http://almanaque.folha.uol.com.br/brasil_1labr1984.htm>. Acesso em: 10 maio 2006.

$<$ http://almanaque.folha.uol.com.br/brasill7abr1984.htm>. Acesso em: 10 maio 2006. 